\title{
Transcriptome analysis reveals differentially expressed IncRNAs between oral squamous cell carcinoma and healthy oral mucosa
}

\author{
Lu Feng ${ }^{1,2}$, John R. Houck ${ }^{1}$, Pawadee Lohavanichbutr ${ }^{1}$, Chu Chen ${ }^{1,3,4}$ \\ ${ }^{1}$ Program in Epidemiology, Division of Public Health Sciences, Fred Hutchinson Cancer Research Center, Seattle, Washington, \\ USA \\ ${ }^{2}$ Department of Head and Neck Surgery, The Affiliated Cancer Hospital of Zhengzhou University, Zhengzhou, Henan, P.R.China \\ ${ }^{3}$ Department of Epidemiology, University of Washington, Seattle, Washington, USA \\ ${ }^{4}$ Department of Otolaryngology, Head and Neck Surgery, University of Washington, Seattle, Washington, USA
}

Correspondence to: Chu Chen, email: cchen@fredhutch.org

Keywords: oral cavity and oropharyngeal squamous cell carcinoma (OSCC), long non-coding RNA, GEO, microarray

Received: October 19, $2016 \quad$ Accepted: March 09, $2017 \quad$ Published: March 18, 2017

Copyright: Feng et al. This is an open-access article distributed under the terms of the Creative Commons Attribution License (CC-BY), which permits unrestricted use, distribution, and reproduction in any medium, provided the original author and source are credited.

\section{ABSTRACT}

Oral cavity and oropharyngeal squamous cell carcinoma (OSCC) is a major cancer type in the head and neck region. To better understand the roles long non-coding RNA (IncRNA) play in OSCC carcinogenesis, we compared the expression levels of 3,054 probe sets for IncRNAs between 167 OSCCs and 45 healthy oral mucosa using an Affymetrix HG U133 plus 2.0 array dataset. We found 658 IncRNA transcripts (790 probe sets) to be significantly differentially expressed using a criteria of FDR $<0.01$, with 36 of them (39 probe sets) showing more than a 2-fold change. We further validated the top differentially expressed IncRNAs in three independent datasets from Gene Expression Omnibus (GEO) repository: GSE42743, GSE9844, and GSE6791. Fourteen IncRNAs (15 probe sets) were validated in all three datasets using the criteria FDR < 0.01: LOC441178, C5orf66-AS1, HCG22, FLG-AS1, CCL14/CCL15CCL14, LOC100506990, TRIP10, PCBP1-AS1, LINC01315, LINC00478, COX10-AS1/ LOC100506974, MLLT4-AS1, MIR31HG, and DUXAP10/LINC01296. Three IncRNAs in the validated list which showed the highest fold change (LOC441178, HCG22 and C5orf66-AS1) were verified by quantitative RT-PCR in a subset of 20 OSCCs and 10 control samples. In silico prediction of their functional role has given us directions for further investigation.

\section{INTRODUCTION}

Oral cavity and oropharyngeal squamous cell carcinoma (OSCC) is the eighth most common cancer among men and fourteenth among women in the U.S. according to recent data [1]. The estimated incidence is 11.1 [SEER, http://seer.cancer.gov/] per 100,000 in the U.S. About 600,000 new cases arise annually worldwide [1-3]. Tobacco and alcohol consumption, as well as infection with high risk human papillomavirus (HPV), have been shown to be the main risk factors of OSCC in the U.S. [2, 4-6]. However, the precise mechanisms of OSCC carcinogenesis are not well understood; and little improvement has been made to the overall prognosis for advanced-stage OSCC in the past two to three decades, leaving the patients and their families with heavy disease burden [7]. There continues to be an urgent need to achieve a better understanding of the mechanisms of oral carcinogenesis in order to aid the discovery of effective therapeutic targets.

It is estimated that $>70 \%$ of the human genome can be transcribed. However, only $2 \%$ are protein-coding and the majority of transcripts are not [8]. These majority transcripts are categorized as non-coding RNA (ncRNA). Except for those "housekeeping" ncRNAs such as tRNAs, rRNAs, there are also other mRNA-like transcripts which can be subdivided by length: small ncRNA $(<200 \mathrm{nt})$ and long ncRNA (> $200 \mathrm{nt}$ ) [8]. Small ncRNAs, like microRNAs, have been studied extensively and there is evidence to suggest that they may play an important role in cancer, including OSCC [9]. However, the study of lncRNAs in cancer has only begun in the last decade [10]. 
The functions of only a handful of lncRNAs have been studied with results showing that they play a role as transcriptional and post-transcriptional regulators. Their reported functions include: 1) Remodeling chromatin state (e.g. HOTAIR or Xist influences chromatin remodeling by recruiting PRC2 [11-13]); 2) Providing stability to proteins or protein complexes (e.g. MALAT1 and NEAT1 serve as molecular scaffolds for proteins within nuclear speckles and paraspeckles [10, 14]); 3) Competing with endogenous RNAs to modulate their functions ( e.g. UCA1 and $M E G 3$ regulate oncogenes by "sponging" miRNAs and decreasing their function $[15,16])$.

Gibb et al. was the first to report the expression of lncRNA in oral mucosa, implying lncRNAs contribute to the oral transcriptome [17]. Subsequent studies have evaluated whether IncRNAs are involved in tumor development by comparing their expressions between cancers and controls. Several such studies reported aberrantly expressed lncRNAs in oral cancers. HOTAIR (HOX transcript antisense RNA) was reported to be upregulated in OSCC $[18,19]$ and laryngeal squamous cell carcinoma [20, 21]. An increase in its expression was associated with metastasis and poor prognosis of OSCC [18]. In 2015, Sharma S. et al. reported HPV16 oncoprotein E7 could be involved in cervical cancer carcinogenesis through regulating HOTAIR expression and function [22]. Whether this molecular event also occurs in HPVrelated oral cancer remains unknown. MALAT1 (metastasis associated lung adenocarcinoma transcript 1) is another reported lncRNA. This large, infrequently spliced noncoding RNA was aberrantly expressed in lung cancer and cervical cancer, and its upregulation is associated with growth and metastasis of several types of cancer, such as colorectal, pancreatic and gastric cancers [23, 24] and in tongue squamous cell carcinoma and OSCC $[23,25]$. Other lncRNAs that have been reported in oral cancer include $M E G 3$, which was down-regulated in tongue cancer [26], and UCA1, which was up-regulated in tongue cancer [27]. Some studies of head and neck cancer [20, 28-30] suggested that lncRNA, including AFAP1-AS1, $A B 209630$, GAS5, and HOTAIR, could potentially serve as predictors of patient outcome or treatment response.

To better understand the role of IncRNAs in OSCC carcinogenesis, and to gain insight for the identification of potentially clinically relevant targets, we used a whole genome approach to examine expression differences of IncRNAs between OSCC and normal oral tissue. Previous studies by Risueño et al. [31], Liao et al. [32] and Michelhaugh et al. [33] have shown that existing microarray data can be mined to study lncRNA transcription. In this study, we developed our own approach to identify and validate a list of significantly dysregulated lncRNAs between OSCC and oral mucosa from healthy individuals using our previously generated microarray data.

\section{RESULTS}

\section{Differentially expressed IncRNA genes between cases and controls}

To identify differentially expressed $\operatorname{lncRNAs}$ between OSCC and control, we used a dataset comprised of 167 OSCCs and 45 oral mucosa samples from healthy controls previously generated using Affymetrix Human Genome U133 Plus 2.0 array (Affymetrix, Santa Clara, CA, USA). Out of 3,054 candidate probe sets that represent 2,172 lncRNA transcripts (see Supplementary Table 1), we found 790 probe sets (representing 658 lncRNAs transcripts) to be significantly differentially expressed with the criteria FDR $<0.01$ (see Supplementary Table 2). Of them, 568 were down-regulated and 222 were up-regulated in cancer. Amongst all, 39 probe sets (36 lncRNA transcripts) have a fold change difference $>2$, with the majority (31 out of 39) of them being downregulated. The two most differentially expressed probe sets identified the same lncRNA LOC 441178 with both showing a greater than 14-fold down-regulation in OSCC compared to control oral mucosa. To validate our findings in external datasets, we analyzed the expression of the top 39 probe sets that were identified in our study in three external datasets downloaded from GEO, adjusting for age and sex. Study participants' characteristics for our study and for these three validation sets are summarized in Table 1. With a criteria of FDR $<0.01$, most of the 39 probes were differentially expressed between cases and controls in at least one of the three GEO datasets. The 15 probe sets (representing 14 lncRNA transcripts) that were differentially expressed in all three validation datasets were as follows: LOC441178, C5orf66-AS1, HCG22, FLGAS1, CCL14/CCL15-CCL14, LOC100506990, TRIP10, PCBP1-AS1, LINC01315, LINC00478, COX10-AS1/ LOC100506974, MLLT4-AS1, MIR31HG, and DUXAP10/ LINC01296. The results on their differential expressions are shown in Table 2.

\section{Verification of LOC441178, HCG22 and C5orf66- AS1 by quantitative RT-PCR}

To confirm the differential expression signals found in the array data, three lncRNAs (LOC441178, HCG22 and C5orf66-AS1) in the validated list showing the highest fold changes were chosen to undergo qRT-PCR testing in a subset of 20 OSCCs and 10 normal controls samples (see Supplementary Table 3). The samples were randomly chosen from the original FHCRC study samples which consist 167 OSCCs and 45 oral mucosa from healthy people. LOC 441178 has two identified transcripts, one shorter transcript that codes for a 93 aa protein, and the other longer transcript is identified as a lncRNA. To confirm that the lncRNA transcript is truly 
Table 1: Characteristics of four microarray datasets used in this study

\begin{tabular}{|c|c|c|c|c|c|}
\hline \multicolumn{2}{|c|}{ Characteristics } & FHCRC dataset [34] & GSE42743 [35] & GSE9844 [36] & GSE6791 [37] \\
\hline \multirow[t]{2}{*}{ Case } & Cancer & 167 (OSCC) & 74 (oral cavity) & 26 (tongue) & 35 (OSCC) \\
\hline & Control & 45 (healthy normal) & 29 (adjacent normal) & 12 (adjacent normal) & 14 (non-cancerous normal) \\
\hline \multirow[t]{2}{*}{ Gender } & Male & 152 & 79 & 29 & 29 \\
\hline & Female & 60 & 24 & 9 & 20 \\
\hline \multirow[t]{3}{*}{ Age } & $<50$ & 64 & 29 & 11 & 7 \\
\hline & $50 \sim 70$ & 118 & 51 & 24 & 31 \\
\hline & $>70$ & 30 & 23 & 3 & 11 \\
\hline
\end{tabular}

differentially expressed, we designed a PCR primer pair that targets only the lncRNA transcript. Figure 1 shows the differential expressions of the three lncRNAs in OSCC and controls $(P<0.05)$. The correlation of Affymetrix array data and PCR results were calculated. Pearson's correlation coefficient value of LOC441178, HCG22 and C5orf66-AS1 were $0.88,0.83$ and 0.72 , respectively (see Supplementary Figure 1).

\section{Prediction of putative targets of IncRNA LOC441178 and functional clustering}

Terai $\mathrm{G}$ et al. [38] have reported a comprehensive interaction database of IncRNA and mRNA based on sequence complementarity. We used that database to predict the targets of the No. 1 differentially expressed lncRNA LOC441178. The top 100 putative targets are shown in Supplementary Table 4. Functional annotation of these putative 100 target genes using DAVID bioinformatics classification tool [39] showed that they are enriched in 8 clusters with suggested functional involvement in cellular motility, ion channel signaling and ATP metabolism (see Table 3).

\section{DISCUSSION}

In this study, we identified 790 significantly differentially expressed probe sets, representing 658 IncRNAs, between OSCCs and normal oral mucosa, with 39 of them, representing 36 lncRNAs, showing more than a 2-fold change in their expression levels. We also used three independent datasets to validate our findings, and 14 lncRNAs were found to be significantly differentially expressed in all data sets. We suspect these differentially expressed lncRNAs in OSCC may be involved in oral cancer carcinogenesis, and they also could serve as new choices for the investigation of potential OSCC biomarkers and/or therapeutic targets. Some of our findings are novel in that of the 14 validated lncRNAs, more than a half ( 8 out of 14) have never been reported to be associated with cancer before: LOC441178, COX10-AS1, PCBP1-AS1, FLG-AS1, MLLT4-AS1, LINC01315, LOC100506990, and CCL15-CCL14. LOC441178 was the top differentially expressed lncRNA in all four datasets, and was confirmed by qRT-PCR in a subset of samples. Prediction of targets of IncRNA LOC441178 in silico using a lncRNA-RNA interactions database[38] showed that LOC441178 will
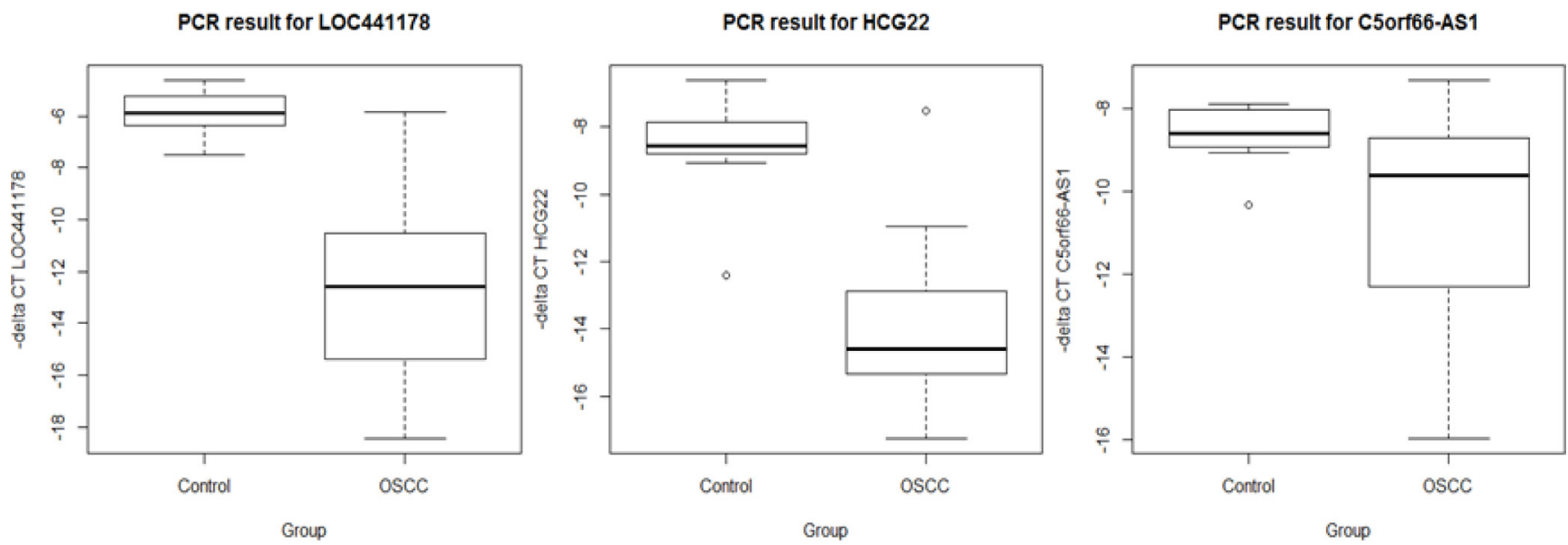

Figure 1: Expression level between OSCC and controls by qRT-PCR. Results shown as delta Ct value standardized to beta actin. Delta $\mathrm{Ct}$ value in $\mathrm{Y}$ axis was transformed by multiplying -1 so that the higher value was corresponding to the higher expression level. 
Table 2: Validation of 39 differentially expressed probe sets between OSCC and control in three independent datasets

\begin{tabular}{|c|c|c|c|c|c|c|c|}
\hline Probe sets ID & Gene Symbol & $\begin{array}{c}\text { Chromosomal } \\
\text { Location }\end{array}$ & $\begin{array}{c}\text { Fold } \\
\text { change in } \\
\text { FHCRC } \\
\text { dataset }\end{array}$ & $\begin{array}{c}Q \text {-value } \\
\text { in } \\
\text { FHCRC } \\
\text { dataset }\end{array}$ & $\begin{array}{l}Q \text {-value in } \\
\text { GSE42743 }\end{array}$ & $\begin{array}{l}Q \text {-value } \\
\text { in } \\
\text { GSE9844 }\end{array}$ & $\begin{array}{l}Q \text {-value in } \\
\text { GSE6791 }\end{array}$ \\
\hline 1563894_at* & LOC 441178 & chr6q27 & -14.50 & 8.83E-49 & $1.00 \mathrm{E}-12$ & $1.11 \mathrm{E}-06$ & $6.09 \mathrm{E}-13$ \\
\hline 1561685_a_at* & LOC 441178 & chr6q27 & -14.23 & 8.83E-49 & $5.22 \mathrm{E}-13$ & $1.11 \mathrm{E}-06$ & $2.26 \mathrm{E}-13$ \\
\hline 1558920_at & $S L C 8 A 1-A S 1$ & chr2p22.1 & -8.43 & $5.85 \mathrm{E}-45$ & $6.51 \mathrm{E}-07$ & 0.02 & $1.83 \mathrm{E}-03$ \\
\hline 236444_x_at & C5orf66-AS1 & chr5q31.1 & -6.60 & $1.91 \mathrm{E}-28$ & $4.32 \mathrm{E}-09$ & $2.29 \mathrm{E}-03$ & $9.62 \mathrm{E}-06$ \\
\hline 227725_at* & ST6GALNAC1 & $\operatorname{chr17q25.1}$ & -5.87 & $1.44 \mathrm{E}-15$ & $1.93 \mathrm{E}-09$ & 0.02 & $1.18 \mathrm{E}-04$ \\
\hline 204919_at* & $\begin{array}{l}\text { PRH1-PRR4/ } \\
\text { PRR4 }\end{array}$ & $\begin{array}{l}\text { chr12p/ } \\
\text { chr12p13 }\end{array}$ & -5.31 & 4.18E-06 & $5.29 \mathrm{E}-03$ & 0.59 & 0.03 \\
\hline 1560767_at* & $H C G 22$ & chr6p21.33 & -3.95 & $1.91 \mathrm{E}-28$ & $5.83 \mathrm{E}-14$ & $2.35 \mathrm{E}-05$ & $1.50 \mathrm{E}-05$ \\
\hline 241014_at & $F L G-A S 1$ & chrlq21.3 & -3.61 & $6.52 \mathrm{E}-35$ & $5.22 \mathrm{E}-13$ & $6.69 \mathrm{E}-06$ & $9.62 \mathrm{E}-06$ \\
\hline 244620_at & $S L C 8 A 1-A S 1$ & chr2p22.1 & -3.29 & $1.81 \mathrm{E}-34$ & $4.33 \mathrm{E}-06$ & 0.04 & $2.14 \mathrm{E}-03$ \\
\hline 224997_x_at & H19/MIR675 & chr11p15.5 & -3.23 & $6.43 \mathrm{E}-04$ & 0.05 & 0.10 & 0.11 \\
\hline 205392_s_at* & $\begin{array}{l}\text { CCL14/CCL15- } \\
\text { CCL14 }\end{array}$ & $\begin{array}{l}\operatorname{chr17q11.2/} \\
\operatorname{chr} 17 q 12\end{array}$ & -2.92 & $2.08 \mathrm{E}-14$ & $1.29 \mathrm{E}-08$ & 7.54E-06 & 7.39E-07 \\
\hline 227917_at & LOC100506990 & chr8p23.1 & -2.77 & $4.44 \mathrm{E}-21$ & $1.93 \mathrm{E}-09$ & $1.04 \mathrm{E}-03$ & $6.38 \mathrm{E}-04$ \\
\hline 242546_at & $\begin{array}{l}D U X A P 10 / \\
L I N C 01296\end{array}$ & $\operatorname{chr} 14 q 11.2$ & 2.75 & $3.56 \mathrm{E}-09$ & $1.49 \mathrm{E}-06$ & 8.29E-03 & $3.18 \mathrm{E}-04$ \\
\hline 202734_at* & TRIP10 & chr19p13.3 & -2.69 & $4.82 \mathrm{E}-33$ & $3.06 \mathrm{E}-06$ & 7.44E-03 & 6.29E-06 \\
\hline 1557389_at & $S H 3 P X D 2 A-A S 1$ & chr10q24.33 & -2.51 & $6.31 \mathrm{E}-14$ & $2.99 \mathrm{E}-03$ & 0.46 & $1.03 \mathrm{E}-03$ \\
\hline 1554097_a_at & MIR31HG & chr9p21.3 & 2.50 & 1.92E-09 & $1.48 \mathrm{E}-08$ & $5.59 \mathrm{E}-03$ & $8.48 \mathrm{E}-03$ \\
\hline 1562921_at & EP300-AS1 & chr22q13.2 & -2.44 & $3.79 \mathrm{E}-14$ & 4.87E-03 & 0.04 & $3.30 \mathrm{E}-03$ \\
\hline 228658_at & MIAT & chr22q12.1 & 2.37 & $9.59 \mathrm{E}-09$ & $2.31 \mathrm{E}-04$ & 0.59 & 0.19 \\
\hline 236573_at & $\begin{array}{l}\text { MIR1-2/ } \\
\text { MIR133A1/ } \\
\text { MIR133A1HG }\end{array}$ & $\operatorname{chr} 18 \mathrm{q} 11.2$ & -2.34 & $2.46 \mathrm{E}-08$ & $5.62 \mathrm{E}-07$ & 0.17 & 0.12 \\
\hline 227969_at & PCBP1-AS1 & chr2p14 & -2.31 & $1.24 \mathrm{E}-35$ & $6.61 \mathrm{E}-08$ & $5.41 \mathrm{E}-06$ & $2.18 \mathrm{E}-04$ \\
\hline 208908_s_at* & $C A S T$ & chr5q15 & -2.26 & $2.93 \mathrm{E}-30$ & 7.59E-06 & 0.02 & $1.33 \mathrm{E}-03$ \\
\hline 229930_at & LINC01315 & $\operatorname{chr} 22 \mathrm{q} 13.2$ & -2.25 & $1.77 \mathrm{E}-22$ & $6.81 \mathrm{E}-09$ & $2.35 \mathrm{E}-05$ & $7.86 \mathrm{E}-06$ \\
\hline 239999_at & LINC00478 & chr21q21.1 & -2.25 & $2.34 \mathrm{E}-11$ & $1.93 \mathrm{E}-09$ & $2.35 \mathrm{E}-05$ & $1.96 \mathrm{E}-06$ \\
\hline 220918_at & RUNX1-IT1 & chr21q22.12 & 2.23 & 4.70E-11 & $3.42 \mathrm{E}-07$ & 0.10 & 0.03 \\
\hline 202672_s_at* & ATF3 & chr1q32.3 & 2.23 & $9.56 \mathrm{E}-06$ & $8.20 \mathrm{E}-05$ & 0.31 & 0.03 \\
\hline 1559361_at & $\begin{array}{l}\text { LOC101927668/ } \\
\text { MACC1 }\end{array}$ & chr7p21.1 & -2.21 & $1.75 \mathrm{E}-13$ & $7.55 \mathrm{E}-04$ & 0.23 & 0.01 \\
\hline 230451_at & $\begin{array}{l}\text { COX10-AS1/ } \\
L O C 100506974\end{array}$ & chr17p12 & -2.20 & $2.23 \mathrm{E}-37$ & $6.63 \mathrm{E}-09$ & $1.11 \mathrm{E}-06$ & $5.16 \mathrm{E}-08$ \\
\hline 219871_at & KLF3-AS1 & chr4p14 & -2.20 & $7.82 \mathrm{E}-19$ & $5.00 \mathrm{E}-08$ & 0.06 & 0.04 \\
\hline 238320_at & MIR612/NEAT1 & chr11q13.1 & 2.15 & $2.35 \mathrm{E}-06$ & 0.02 & 0.29 & 0.02 \\
\hline 207467_x_at* & $C A S T$ & chr5q15 & -2.14 & $1.22 \mathrm{E}-30$ & $3.68 \mathrm{E}-06$ & 0.01 & $1.33 \mathrm{E}-03$ \\
\hline 1557146_a_at & SSTR5-AS1 & chr16p13.3 & -2.12 & $7.86 \mathrm{E}-07$ & 0.02 & 0.40 & 0.19 \\
\hline 210409 at* & MLLT4-AS1 & chr6q27 & -2.12 & $1.63 \mathrm{E}-30$ & $6.45 \mathrm{E}-07$ & $1.92 \mathrm{E}-04$ & $2.38 \mathrm{E}-10$ \\
\hline 226382 at* & LOC283070 & chr10p13 & -2.09 & $9.82 \mathrm{E}-14$ & $8.52 \mathrm{E}-06$ & $9.58 \mathrm{E}-03$ & 0.03 \\
\hline
\end{tabular}




\begin{tabular}{|c|c|c|c|c|c|c|c|}
\hline 228370_at & $\begin{array}{l}\text { IPW/ } \\
\text { LOC101930404/ } \\
\text { PWARSN/ } \\
\text { SNORD107/ } \\
\text { SNORD115-13/ } \\
\text { SNORD115-26/ } \\
\text { SNORD115-7/ } \\
\text { SNORD116-22/ } \\
\text { SNORD116-28/ } \\
\text { SNORD116-4 }\end{array}$ & $\operatorname{chr} 15 \mathrm{q} 11.2$ & -2.09 & $9.34 \mathrm{E}-08$ & $1.55 \mathrm{E}-06$ & 0.02 & 0.04 \\
\hline 232034_at & LINC00537 & chr9q21.11 & -2.05 & $1.33 \mathrm{E}-11$ & 0.02 & 0.10 & 0.10 \\
\hline 233565_s_at* & $\begin{array}{l}F K B P 1 A- \\
S D C B P 2 / \\
S D C B P 2\end{array}$ & chr20p13 & -2.05 & $1.23 \mathrm{E}-09$ & $4.78 \mathrm{E}-04$ & 0.17 & 0.06 \\
\hline 229635_at & LINC01094 & chr4q21.21 & 2.04 & $4.78 \mathrm{E}-12$ & $9.33 \mathrm{E}-05$ & 0.05 & 0.01 \\
\hline 228564_at & LINC01116 & chr2q31.1 & 2.03 & $3.40 \mathrm{E}-10$ & 4.94E-08 & 0.10 & 0.03 \\
\hline 227061_at & LINC01279 & chr3q13.2 & -2.02 & $1.63 \mathrm{E}-03$ & $5.34 \mathrm{E}-06$ & $2.29 \mathrm{E}-03$ & 0.19 \\
\hline
\end{tabular}

Gene symbols in bold font refer to those that were validated in all three external datasets. * Probe sets that map to both coding and non-coding transcripts.

potentially interact with both coding and non-coding RNAs, some of which are related to cancer, such as coding mRNA MUC16/CA125[40], and non-coding RNA KCNQ1OT1 [41]. Functional clustering of these predicted targets give us an initial glance at the biological functions associated with this top lncRNA. With more than 100 fold change difference between cancer and control in qRT-PCR testing, it may have strong potential as a diagnostic biomarker for OSCC. HCG22 was found to be downregulated in oral cancer and its lower expression was reported to be associated with poor survival in a recent lncRNA study using TCGA data [42]. While our qRT-PCR results confirm the down-regulation of HCG22 in OSCC, we did not find an association between $H_{C}{ }^{22}$ expression levels and survival in our study population (data not shown). C5orf66-AS1, also known as Epist, was previously found to be downregulated and may act as a tumor suppressor in esophageal squamous cell carcinoma [43]. It has the same expression pattern in OSCC (see Figure 1), suggesting that $C 5$ orf66-AS1 may be involved in multiple cancer types that occur in the upper aerodigestive tract. Within $5 \mathrm{~kb}$ distance of C5orf66-AS1 is pituitary homeobox 1 (PITX1). PITX1 expression level was found recently to be a novel predictor for treatment response of head and neck cancer [44]. Further study is needed to see if $C 5$ orf66- $A S 1$ could be a regulator of this neighboring PITX1 gene. MIR31 host gene (MIR31HG), also named IncRNA LOC554202, was found to be down-regulated in gastric cancer[45] and bladder cancer[46], but up-regulated in breast cancer[47]. Further, there is evidence showing that it was upregulated in oncogene-induced senescence process; and knockdown of MIR31HG induced a tumor suppressor p16INK4A dependent senescence phenotype, which might link it to HPV-related cancer carcinogenesis
[48]. In our study, MIR31HG expression does not appear to be significantly different between HPV-positive OPC (oropharyngeal cancer) and HPV-negative OPC ( $P=0.02$, lower in HPV-positive OPC). However, we found it was significantly differentially expressed between subsites of OSCC (OPC vs. OCC (oral cavity cancer), $P=9.29 \mathrm{E}-07$, lower in OPC), and between smokers and non-smokers $(P=5.05 \mathrm{E}-05$, lower in smokers). LINC01296 was reported to be dysregulated in colorectal cancer and was suspected to be a potential prognostic biomarker [49]. The expression level of the probe set for LINC01296 in our study was also significantly different between OSCC and controls, suggesting that this lncRNA may be involved in carcinogenesis process.

Some previously reported cancer-associated IncRNAs, such as HOTAIR, UCA1, and MALAT1, were found to be differentially expressed in our study, but none was in our top, validated list. Interestingly, some lncRNAs showed opposite expression direction in our study than in previous studies focusing on individual lncRNAs in head and neck cancers. Supplementary Table 5 shows their deregulation status in other studies and in our data. The discrepancies perhaps could be related to differences in sample size, platform used, origin of the control tissue used, or tumor site.

There are a large number of IncRNAs with unknown function that have yet to be studied. While genome wide study of lncRNA is a good approach to unveil more IncRNAs that may be involved in carcinogenesis or may represent potential therapeutic targets, making direct comparisons of results from various studies has been difficult. A major challenge is the use of different assay platforms by different studies. The lack of standardization in gene nomenclature is also an issue. Several studies of 
Table 3: Functional clustering of the putative predicted targets of $L O C 441178$

Annotation Cluster 1

Enrichment Score: 4.07393095028667

\begin{tabular}{|c|c|c|c|c|}
\hline Category & Term & Count & $\%$ & $P$ Value \\
\hline GOTERM_MF_DIRECT & GO:0016887 ATPase activity & 11 & 11.22449 & $1.91 \mathrm{E}-08$ \\
\hline GOTERM_MF_DIRECT & GO:0003777 microtubule motor activity & 7 & 7.142857 & $2.46 \mathrm{E}-06$ \\
\hline GOTERM_CC_DIRECT & GO:0030286 dynein complex & 5 & 5.102041 & $3.80 \mathrm{E}-06$ \\
\hline GOTERM_BP_DIRECT & GO:0007018 microtubule-based movement & 6 & 6.122449 & 5.59E-05 \\
\hline GOTERM_CC_DIRECT & GO:0005874 microtubule & 8 & 8.163265 & $8.78 \mathrm{E}-04$ \\
\hline GOTERM MF DIRECT & GO:0005524 ATP binding & 17 & 17.34694 & 0.002009 \\
\hline KEGG_PATHWAY & hsa05016:Huntington's disease & 6 & 6.122449 & 0.003745 \\
\hline GOTERM_CC_DIRECT & GO:0005929 cilium & 4 & 4.081633 & 0.038842 \\
\hline
\end{tabular}

Annotation Cluster 2

Enrichment Score: 3.17701545165616

\begin{tabular}{|c|c|c|c|c|}
\hline Category & Term & Count & $\%$ & $P$ Value \\
\hline GOTERM_CC_DIRECT & GO:0042383 sarcolemma & 7 & 7.142857 & $3.92 \mathrm{E}-06$ \\
\hline GOTERM_BP_DIRECT & $\begin{array}{l}\text { GO:0010881 regulation of cardiac muscle contraction } \\
\text { by regulation of the release of sequestered calcium ion }\end{array}$ & 4 & 4.081633 & $1.14 \mathrm{E}-04$ \\
\hline GOTERM_BP_DIRECT & $\begin{array}{l}\text { GO:0010882 regulation of cardiac muscle contraction } \\
\text { by calcium ion signaling }\end{array}$ & 3 & 3.061224 & $5.23 \mathrm{E}-04$ \\
\hline GOTERM_BP_DIRECT & GO:0002027 regulation of heart rate & 4 & 4.081633 & $6.12 \mathrm{E}-04$ \\
\hline GOTERM_CC_DIRECT & GO:0030315 T-tubule & 4 & 4.081633 & $8.67 \mathrm{E}-04$ \\
\hline GOTERM_BP_DIRECT & GO:0060048 cardiac muscle contraction & 4 & 4.081633 & 0.001524 \\
\hline GOTERM_MF_DIRECT & GO:0044325 ion channel binding & 5 & 5.102041 & 0.002229 \\
\hline GOTERM_BP_DIRECT & GO:0035994 response to muscle stretch & 3 & 3.061224 & 0.002902 \\
\hline GOTERM CC DIRECT & GO:0014704 intercalated disc & 3 & 3.061224 & 0.020809 \\
\hline
\end{tabular}

Annotation Cluster 3

Enrichment Score: $\mathbf{2 . 9 5 5 7 7 1 8 5 1 0 1 3 7 2 7 4}$

\begin{tabular}{|c|c|c|c|c|}
\hline Category & Term & Count & $\%$ & $P$ Value \\
\hline GOTERM_BP_DIRECT & GO:0045053 protein retention in Golgi apparatus & 3 & 3.061224 & $2.51 \mathrm{E}-04$ \\
\hline GOTERM_BP_DIRECT & GO:0006623 protein targeting to vacuole & 3 & 3.061224 & $6.95 \mathrm{E}-04$ \\
\hline GOTERM CC DIRECT & GO:0019898 extrinsic component of membrane & 4 & 4.081633 & 0.007787 \\
\hline
\end{tabular}

Annotation Cluster 4

Enrichment Score: 2.830552043347304

\begin{tabular}{|l|l|c|c|c|}
\hline \multicolumn{1}{c}{ Category } & \multicolumn{1}{c}{ Term } & Ount & P Value \\
\hline GOTERM_CC_DIRECT & GO:0042383 sarcolemma & 7 & 7.142857 & $3.92 \mathrm{E}-06$ \\
\hline GOTERM_CC_DIRECT & GO:0043034 costamere & 4 & 4.081633 & $1.07 \mathrm{E}-04$ \\
\hline GOTERM_CC_DIRECT & GO:0045211 postsynaptic membrane & 7 & 7.142857 & $6.23 \mathrm{E}-04$ \\
\hline GOTERM_MF_DIRECT & GO:0005200 structural constituent of cytoskeleton & 3 & 3.061224 & 0.099947 \\
\hline GOTERM_CC_DIRECT & GO:0045121 membrane raft & 3 & 3.061224 & 0.270657 \\
\hline
\end{tabular}

Annotation Cluster 5

Enrichment Score: 1.6982330480366516

\begin{tabular}{|c|c|c|c|c|}
\hline Category & Term & Count & $\%$ & $P$ Value \\
\hline GOTERM_BP_DIRECT & GO:0060048 cardiac muscle contraction & 4 & 4.081633 & 0.001524 \\
\hline KEGG_PATHWAY & hsa05410:Hypertrophic cardiomyopathy (HCM) & 3 & 3.061224 & 0.068115 \\
\hline KEGG PATHWAY & hsa05414:Dilated cardiomyopathy & 3 & 3.061224 & 0.077481 \\
\hline
\end{tabular}

Annotation Cluster 6

Enrichment Score: 1.1092710148648803

\begin{tabular}{|c|c|c|c|c|}
\hline Category & Term & Count & $\%$ & $P$ Value \\
\hline GOTERM_MF_DIRECT & GO:0016874 ligase activity & 6 & 6.122449 & 0.010124 \\
\hline GOTERM_MF_DIRECT & GO:0004842 ubiquitin-protein transferase activity & 5 & 5.102041 & 0.076177 \\
\hline KEGG_PATHWAY & hsa04120:Ubiquitin mediated proteolysis & 3 & 3.061224 & 0.173404 \\
\hline
\end{tabular}




\begin{tabular}{|c|c|c|c|c|}
\hline GOTERM_BP_DIRECT & GO:0016567 protein ubiquitination & 4 & 4.081633 & 0.273313 \\
\hline \multicolumn{5}{|c|}{$\begin{array}{l}\text { Annotation Cluster } 7 \\
\text { Enrichment Score: } 0.898891114842629\end{array}$} \\
\hline Category & Term & Count & $\%$ & $P$ Value \\
\hline GOTERM_MF_DIRECT & $\begin{array}{l}\text { GO:0005089 Rho guanyl-nucleotide exchange factor } \\
\text { activity }\end{array}$ & 3 & 3.061224 & 0.053963 \\
\hline GOTERM_BP_DIRECT & $\begin{array}{l}\text { GO:0035023 regulation of Rho protein signal } \\
\text { transduction }\end{array}$ & 3 & 3.061224 & 0.063457 \\
\hline GOTERM_MF_DIRECT & $\begin{array}{l}\text { GO:0005085 guanyl-nucleotide exchange factor } \\
\text { activity }\end{array}$ & 3 & 3.061224 & 0.112325 \\
\hline GOTERM_BP_DIRECT & $\begin{array}{l}\text { GO:0051056 regulation of small GTPase mediated } \\
\text { signal transduction }\end{array}$ & 3 & 3.061224 & 0.147561 \\
\hline GOTERM_BP_DIRECT & GO:0043547 positive regulation of GTPase activity & 6 & 6.122449 & 0.158154 \\
\hline GOTERM_BP_DIRECT & GO:0043065 positive regulation of apoptotic process & 3 & 3.061224 & 0.450355 \\
\hline \multicolumn{5}{|c|}{$\begin{array}{l}\text { Annotation Cluster } 8 \\
\text { Enrichment Score: } 0.8894138004429241\end{array}$} \\
\hline Category & Term & Count & $\%$ & $P$ Value \\
\hline GOTERM_MF_DIRECT & GO:0004672 protein kinase activity & 5 & 5.102041 & 0.09728 \\
\hline GOTERM_MF_DIRECT & GO:0004674 protein serine/threonine kinase activity & 5 & 5.102041 & 0.11034 \\
\hline GOTERM_BP_DIRECT & GO:0006468 protein phosphorylation & 5 & 5.102041 & 0.199986 \\
\hline
\end{tabular}

head and neck squamous cell carcinomas (HNSCC) have been carried out based on deep sequencing data from TCGA [42, 50, 51]. Two other studies have looked at lncRNA expression using re-annotated microarray data in OSCC. Even when the same microarray platform or a different version of the same microarray platform was used, difficulty in direct comparison remains. Gao et al. [52] found eight differentially expressed lncRNAs by comparing 26 tongue squamous cell carcinomas versus 12 controls, using the same Affymetrix U133 Plus 2.0 Gene Chip array data like we did. None of the eight appeared in our differential expression list. Differences in tumor site, sample size, and probe sets reannotation processing may be the reasons between their results and ours. Zhang et al. [53] compared 57 OSCCs and 22 normal controls using an Affymetrix Human Exon 1.0 Array. In their results, 160 lncRNAs were found to be dysregulated in cancer, of which seven were found in our 658 lncRNA list (LOC645949, LINC00896, FAM99B, LINC00167, LINC01056, SND1-IT1, NCBP2-AS2). The reasons of so few overlaps are unknown and could be related to different version of the Affymetrix platform used and the difference in data processing. Zhang et al. excluded probe sets that map to multiple transcripts in their analysis; while we did not. Excluding probe sets that also identify coding transcripts may mean a loss of potential lncRNA of interest. In our study, we chose to keep those probe sets in the initial analysis, because in some cases, it is possible to determine lncRNA transcript expression status more definitively through other methodologies such as quantitative RT-PCR. This approach allowed us to identify our most differentially expressed lncRNA LOC 441178.

The recent development of using CRISPRi method for high throughput functional screening of lncRNAs has increased the number of lncRNAs with known functions [54]. However, this is beyond the scope of the current report. In silico prediction of the potential targets and the pathway analysis of these targets gave us some suggestion to the possible biological functions of our top differentially expressed lncRNA. However, further research is needed to explore more on these functions and the potential usage as biomarkers and/or therapeutic targets for OSCC.

\section{MATERIALS AND METHODS}

\section{Gene expression array data and identification of IncRNAs}

The gene expression microarray data used in this study was generated previously by our group as part of an OralChip study at the Fred Hutchinson Cancer Research Center (FHCRC). The study was designed to identify gene expression profiles that are related to clinical outcomes of OSCC $[34,35,55,56]$. The microarray data were generated using the Affymetrix Human Genome U133 Plus 2.0 array (Affymetrix, Santa Clara, CA, USA) and were deposited in the Gene Expression Omnibus (GEO) Repository under the general accession number GSE30784. The dataset has 212 samples in total, 167 of them are OSCCs and 45 of them are oral mucosa from healthy controls. The samples and patients' clinical data including age, gender, tumor site, stage, and HPV status were obtained from the original OralChip study. This investigation has been approved by the institutional review office of Fred Hutchinson Cancer Research Center. All microarray data have passed two rounds of quality control checks $[34,56]$. CEL files were 
preprocessed and normalized using RMA algorithm in Partek Genomics Suite ${ }^{\mathrm{TM}}$ software version 6.6. To determine the candidate probe sets on the microarray that represent lncRNAs, first, we matched lncRNAs identified by HGNC (HUGO Gene Nomenclature Committee) Database [57] (downloaded from http://www.genenames. org/ at 1/27/2016) with Affymetrix probe ID using Entrez gene ID or Ensemble gene ID. 2,183 probe sets were matched to transcripts identified as "RNA, long noncoding" by HGNC; second, we identified 2,488 probe sets mapped to IncRNA from the Affymetrix annotation file (downloaded from http:/www.affymetrix.com/ at $1 / 25 / 2016$, netaffx-build=35) for the U133 2.0 Plus array. After removal of 1,617 duplicates, we obtained a final list of 3,054 probe sets that represent 2,172 lncRNA transcripts.

\section{Statistical analysis}

The statistical analysis of differentially expressed lncRNA (between cases and controls) was performed using linear regression, adjusting for age and sex. The false discovery rate (FDR) of 0.01 and a 2 -fold difference in expression between the two groups were used as criteria to select the differentially expressed lncRNA. All analyses were performed using $\mathrm{R}$ version 3.3.0.

\section{Validation using independent datasets}

In order to validate our findings, we searched Gene Expression Omnibus (GEO) (http://www.ncbi.nlm.nih. gov/geo/) for datasets with OSCC and normal control samples that also used the Affymetrix U133 Plus 2.0 Gene Chip array. Three datasets were identified: GSE42743 with 74 oral cavity squamous cell carcinoma and 29 adjacent normal tissue [35]; GSE9844 with 26 tongue squamous cell carcinoma and 12 matched adjacent normal tissue [36]; and GSE6791 comprised of 28 cervical cancers, 42 head and neck cancers and 14 site-matched normal oral tissue [37]. We used these three data sets to validate our findings after excluding samples of irrelevant anatomic site and samples containing missing data. The false discovery rate $($ FDR $)<0.01$ was used as criteria in each dataset during validation comparison.

\section{Quantitative reverse transcription polymerase chain reaction (qRT-PCR)}

Among the validated list of lncRNAs, we chose three (LOC441178, C5orf66-AS1 and HCG22) with the highest fold change to do further validation by performing qRT-PCR using a subset of 20 oral cancer samples and 10 control samples randomly chosen from samples in the OralChip study. Each sample was assayed in triplicate in $10 \mathrm{uL}$ reaction volumes using the QuantiTect SYBR
Green RT-PCR kit (Qiagen, Valencia, CA, USA) on a 7900HT Sequence Detection System (Life Technologies, Carlsbad, CA, USA). The cycling conditions were as follows: $30 \mathrm{~min}$ incubation at $50^{\circ} \mathrm{C}, 15 \mathrm{~min}$ incubation at $95^{\circ} \mathrm{C}$, and 40 cycles of $15 \mathrm{~s}$ at $94^{\circ} \mathrm{C}, 30 \mathrm{~s}$ at $55^{\circ} \mathrm{C}$, and 30 $\mathrm{s}$ at $72^{\circ} \mathrm{C}$. Ten-point standard curves were generated using Total RNA - Human Normal Tissue Tongue (Biochain Inst., Newark, CA, USA) for all three genes. The linear correlation coefficient (R2) was $\geq 0.99$ for all runs. The mean threshold cycle $(\mathrm{Ct})$ values were calculated from the triplicate $\mathrm{Ct}$ values. Samples that had $\mathrm{Ct}$ values with $\mathrm{SD}>0.35$ in their triplicate run were repeated. Mean $\mathrm{Ct}$ values were standardized to the mean $\mathrm{Ct}$ value of beta actin housekeeping gene (Quantitect primers (Qiagen, Valencia, CA, USA). Correlations between qRT-PCR and microarray data were performed using $\mathrm{R}$ Stats Package. Primer pairs used for each gene were as follows: LOC441178: Forward primer GGGTATTTTGTGC TCCCCCA; Reverse primer CAGGCACTGAAGGTTCG GAT; HCG22: Forward primer ACAGCAGTGAAACC CACCA; Reverse primer GAAGCCCAATCCAACA AAGAGC; C5orf66-AS1: Forward primer GCTTCGCGTC AAGAGGGTAT; Reverse primer AAGCCGCGGGAA TGTCTTTA. $P$ value was calculated using student's t test between groups.

\section{Functional predictions}

Prediction of the putative targets of lncRNA LOC 441178 was done using a comprehensive interaction database of IncRNA-mRNA which was reported by Terai G et al. [38] in 2016. GO ontology and KEGG pathway analysis and functional clustering of the top 100 targets was done by a gene functional classification tool, DAVID Bioinformatics Resources 6.8, NIAID/NIH [39]. The enrichment thresholds were by the web tool default and the enrichment score was calculated automatically by the tool.

\section{Authors' contributions}

Study design: Lu Feng, John R. Houck, Pawadee Lohavanichbutr, and Chu Chen; Data access (OralChip study data access, GEO data download): Pawadee Lohavanichbutr, Lu Feng, Chu Chen; Data Analysis and interpretation: Lu Feng, Pawadee Lohavanichbutr, John R. Houck, Chu Chen; PCR conduct: Lu Feng, John R. Houck; Manuscript writing, review, and/or revision: Lu Feng, John R. Houck, Pawadee Lohavanichbutr, and Chu Chen; Study supervision: Chu Chen.

\section{ACKNOWLEDGMENTS}

We would like to thank the Affiliated Cancer Hospital of Zhengzhou University, Zhengzhou, Henan, 
P.R.China, for providing support to L. Feng for visiting and conducting research at Fred Hutchinson Cancer Research Center.

\section{CONFLICTS OF INTEREST}

The authors declare no potential conflicts of interest.

\section{FUNDING}

This work was also supported by a grant from the U.S. National Cancer Institute, National Institute of Health RO1CA 095419 (to CC) with additional funds from the Fred Hutchinson Cancer Research Center.

\section{REFERENCES}

1. Ryerson AB, Eheman CR, Altekruse SF, Ward JW, Jemal A, Sherman RL, Henley SJ, Holtzman D, Lake A, Noone AM, Anderson RN, Ma J, Ly KN, et al. Annual Report to the Nation on the Status of Cancer, 1975-2012, featuring the increasing incidence of liver cancer. Cancer. 2016; 122:1312-37. doi: 10.1002/cncr.29936.

2. Leemans CR, Braakhuis BJ, Brakenhoff RH. The molecular biology of head and neck cancer. Nat Rev Cancer. 2011; 11:9-22. doi: 10.1038/nrc2982.

3. Warnakulasuriya S. Global epidemiology of oral and oropharyngeal cancer. Oral Oncol. 2009; 45:309-16. doi: 10.1016/j.oraloncology.2008.06.002.

4. Gillison ML, Chaturvedi AK, Anderson WF, Fakhry C. Epidemiology of Human Papillomavirus-Positive Head and Neck Squamous Cell Carcinoma. J Clin Oncol. 2015; 33:3235-42. doi: 10.1200/jco.2015.61.6995.

5. Lewis A, Kang R, Levine A, Maghami E. The New Face of Head and Neck Cancer: The HPV Epidemic. Oncology (Williston Park). 2015; 29:616-26.

6. Curado MP, Boyle P. Epidemiology of head and neck squamous cell carcinoma not related to tobacco or alcohol. Curr Opin Oncol. 2013; 25:229-34. doi: 10.1097/ CCO.0b013e32835ff48c.

7. Carvalho AL, Nishimoto IN, Califano JA, Kowalski LP. Trends in incidence and prognosis for head and neck cancer in the United States: a site-specific analysis of the SEER database. Int J Cancer. 2005; 114:806-16. doi: 10.1002/ ijc. 20740 .

8. Gutschner T, Diederichs S. The hallmarks of cancer: a long non-coding RNA point of view. RNA Biol. 2012; 9:703-19. doi: 10.4161/rna.20481.

9. Min A, Zhu C, Peng S, Rajthala S, Costea DE, Sapkota D. MicroRNAs as Important Players and Biomarkers in Oral Carcinogenesis. Biomed Res Int. 2015; 2015: 186904. doi: $10.1155 / 2015 / 186904$

10. Maruyama R, Suzuki H. Long noncoding RNA involvement in cancer. BMB Rep. 2012; 45:604-11.
11. Quinn JJ, Chang HY. Unique features of long non-coding RNA biogenesis and function. Nat Rev Genet. 2016; 17:47-62. doi: 10.1038/nrg.2015.10.

12. Bartonicek N, Maag JL, Dinger ME. Long noncoding RNAs in cancer: mechanisms of action and technological advancements. Mol Cancer. 2016; 15: 43. doi: 10.1186/ s12943-016-0530-6.

13. Davidovich $\mathrm{C}$, Cech TR. The recruitment of chromatin modifiers by long noncoding RNAs: lessons from PRC2. Rna. 2015; 21:2007-22. doi: 10.1261/rna.053918.115.

14. Clemson CM, Hutchinson JN, Sara SA, Ensminger AW, Fox AH, Chess A, Lawrence JB. An architectural role for a nuclear noncoding RNA: NEAT1 RNA is essential for the structure of paraspeckles. Mol Cell. 2009; 33:717-26. doi: 10.1016/j.molcel.2009.01.026.

15. Nie W, Ge HJ, Yang XQ, Sun X, Huang H, Tao X, Chen WS, Li B. LncRNA-UCA1 exerts oncogenic functions in nonsmall cell lung cancer by targeting miR-193a-3p. Cancer Lett. 2016; 371:99-106. doi: 10.1016/j.canlet.2015.11.024.

16. Peng W, Si S, Zhang Q, Li C, Zhao F, Wang F, Yu J, Ma R. Long non-coding RNA MEG3 functions as a competing endogenous RNA to regulate gastric cancer progression. J Exp Clin Cancer Res. 2015; 34: 79. doi: 10.1186/s13046015-0197-7.

17. Gibb EA, Enfield KS, Stewart GL, Lonergan KM, Chari R, Ng RT, Zhang L, MacAulay CE, Rosin MP, Lam WL. Long non-coding RNAs are expressed in oral mucosa and altered in oral premalignant lesions. Oral Oncol. 2011; 47:1055-61. doi: 10.1016/j.oraloncology.2011.07.008.

18. Wu Y, Zhang L, Zhang L, Wang Y, Li H, Ren X, Wei F, Yu W, Liu T, Wang X, Zhou X, Yu J, Hao X. Long noncoding RNA HOTAIR promotes tumor cell invasion and metastasis by recruiting EZH2 and repressing E-cadherin in oral squamous cell carcinoma. Int J Oncol. 2015; 46:258694. doi: 10.3892/ijo.2015.2976.

19. Wu J, Xie H. Expression of long noncoding RNA-HOX transcript antisense intergenic RNA in oral squamous cell carcinoma and effect on cell growth. Tumour Biol. 2015; 36:8573-8. doi: 10.1007/s13277-015-3598-5.

20. Wang J, Zhou Y, Lu J, Sun Y, Xiao H, Liu M, Tian L. Combined detection of serum exosomal miR-21 and HOTAIR as diagnostic and prognostic biomarkers for laryngeal squamous cell carcinoma. Med Oncol. 2014; 31 : 148. doi: 10.1007/s12032-014-0148-8.

21. Li D, Feng J, Wu T, Wang Y, Sun Y, Ren J, Liu M. Long intergenic noncoding RNA HOTAIR is overexpressed and regulates PTEN methylation in laryngeal squamous cell carcinoma. Am J Pathol. 2013; 182:64-70. doi: 10.1016/j. ajpath.2012.08.042.

22. Sharma S, Mandal P, Sadhukhan T, Roy Chowdhury R, Ranjan Mondal N, Chakravarty B, Chatterjee T, Roy S, Sengupta S. Bridging Links between Long Noncoding RNA HOTAIR and HPV Oncoprotein E7 in Cervical Cancer Pathogenesis. Sci Rep. 2015; 5: 11724. doi: 10.1038/ srep11724. 
23. Zhou X, Liu S, Cai G, Kong L, Zhang T, Ren Y, Wu Y, Mei M, Zhang L, Wang X. Long Non Coding RNA MALAT1 Promotes Tumor Growth and Metastasis by inducing Epithelial-Mesenchymal Transition in Oral Squamous Cell Carcinoma. Sci Rep. 2015; 5: 15972. doi: 10.1038/srep15972.

24. Yang L, Bai HS, Deng Y, Fan L. High MALAT1 expression predicts a poor prognosis of cervical cancer and promotes cancer cell growth and invasion. Eur Rev Med Pharmacol Sci. 2015; 19:3187-93.

25. Fang Z, Zhang S, Wang Y, Shen S, Wang F, Hao Y, Li Y, Zhang B, Zhou Y, Yang H. Long non-coding RNA MALAT-1 modulates metastatic potential of tongue squamous cell carcinomas partially through the regulation of small proline rich proteins. BMC Cancer. 2016; 16:706. doi: 10.1186/s12885-016-2735-x.

26. Jia LF, Wei SB, Gan YH, Guo Y, Gong K, Mitchelson K, Cheng J, Yu GY. Expression, regulation and roles of miR26a and MEG3 in tongue squamous cell carcinoma. Int J Cancer. 2014; 135:2282-93. doi: 10.1002/ijc.28667.

27. Fang Z, Wu L, Wang L, Yang Y, Meng Y, Yang H. Increased expression of the long non-coding RNA UCA1 in tongue squamous cell carcinomas: a possible correlation with cancer metastasis. Oral Surg Oral Med Oral Pathol Oral Radiol. 2014; 117:89-95. doi: 10.1016/j.oooo.2013.09.007.

28. Bo H, Gong Z, Zhang W, Li X, Zeng Y, Liao Q, Chen P, Shi L, Lian Y, Jing Y, Tang K, Li Z, Zhou Y, et al. Upregulated long non-coding RNA AFAP1-AS1 expression is associated with progression and poor prognosis of nasopharyngeal carcinoma. Oncotarget. 2015; 6:20404-18. doi: 10.18632/ oncotarget.4057.

29. Zhou J, Li M, Yu W, Li W, Wang J, Xiang X, Li G, Pan X, Lei D. AB209630, a long non-coding RNA decreased expression in hypopharyngeal squamous cell carcinoma, influences proliferation, invasion, metastasis, and survival. Oncotarget. 2016; 7:14628-38. doi: 10.18632/ oncotarget.7403.

30. Fayda M, Isin M, Tambas M, Guveli M, Meral R, Altun M, Sahin D, Ozkan G, Sanli Y, Isin H, Ozgur E, Gezer U. Do circulating long non-coding RNAs (lncRNAs) (LincRNA-p21, GAS 5, HOTAIR) predict the treatment response in patients with head and neck cancer treated with chemoradiotherapy? Tumour Biol. 2015; 37:3969-78. doi: 10.1007/s13277-015-4189-1.

31. Risueno A, Fontanillo C, Dinger ME, De Las Rivas J. GATExplorer: genomic and transcriptomic explorer; mapping expression probes to gene loci, transcripts, exons and ncRNAs. BMC Bioinformatics. 2010; 11:221. doi: 10.1186/1471-2105-11-221.

32. Liao Q, Xiao H, Bu D, Xie C, Miao R, Luo H, Zhao G, Yu K, Zhao H, Skogerbo G, Chen R, Wu Z, Liu C, et al. ncFANs: a web server for functional annotation of long non-coding RNAs. Nucleic Acids Res. 2011; 39:W118-24. doi: 10.1093/nar/gkr432.

33. Michelhaugh SK, Lipovich L, Blythe J, Jia H, Kapatos G, Bannon MJ. Mining Affymetrix microarray data for long non- coding RNAs: altered expression in the nucleus accumbens of heroin abusers. J Neurochem. 2011; 116:459-66. doi: 10.1111/j.1471-4159.2010.07126.x.

34. Chen C, Mendez E, Houck J, Fan W, Lohavanichbutr P, Doody D, Yueh B, Futran ND, Upton M, Farwell DG, Schwartz SM, Zhao LP. Gene expression profiling identifies genes predictive of oral squamous cell carcinoma. Cancer Epidemiol Biomarkers Prev. 2008; 17:2152-62. doi: 10.1158/1055-9965.EPI-07-2893.

35. Lohavanichbutr P, Mendez E, Holsinger FC, Rue TC, Zhang Y, Houck J, Upton MP, Futran N, Schwartz SM, Wang P, Chen C. A 13-gene signature prognostic of HPVnegative OSCC: discovery and external validation. Clin Cancer Res. 2013; 19:1197-203. doi: 10.1158/1078-0432. CCR-12-2647.

36. Ye H, Yu T, Temam S, Ziober BL, Wang J, Schwartz JL, Mao L, Wong DT, Zhou X. Transcriptomic dissection of tongue squamous cell carcinoma. BMC Genomics. 2008; 9:69. doi: 10.1186/1471-2164-9-69.

37. Pyeon D, Newton MA, Lambert PF, den Boon JA, Sengupta S, Marsit CJ, Woodworth CD, Connor JP, Haugen TH, Smith EM, Kelsey KT, Turek LP, Ahlquist P. Fundamental differences in cell cycle deregulation in human papillomavirus-positive and human papillomavirusnegative head/neck and cervical cancers. Cancer Res. 2007; 67:4605-19. doi: 10.1158/0008-5472.can-06-3619.

38. Terai G, Iwakiri J, Kameda T, Hamada M, Asai K. Comprehensive prediction of lncRNA-RNA interactions in human transcriptome. BMC Genomics. 2016; 17:12. doi: 10.1186/s12864-015-2307-5.

39. Huang da W, Sherman BT, Lempicki RA. Systematic and integrative analysis of large gene lists using DAVID bioinformatics resources. Nat Protoc. 2009; 4:44-57. doi: 10.1038/nprot.2008.211.

40. Geng XF, Du M, Han JX, Zhang M, Tang XF, Xing RD. Saliva CA125 and TPS levels in patients with oral squamous cell carcinoma. Int J Biol Markers. 2013; 28:216-20. doi: 10.5301/jbm.5000001.

41. Nakano S, Murakami $K$, Meguro $M$, Soejima $H$, Higashimoto K, Urano T, Kugoh H, Mukai T, Ikeguchi M, Oshimura M. Expression profile of LIT1/KCNQ1OT1 and epigenetic status at the KvDMR1 in colorectal cancers. Cancer Sci. 2006; 97:1147-54. doi: 10.1111/j.13497006.2006.00305.x.

42. Nohata N, Abba MC, Gutkind JS. Unraveling the oral cancer lncRNAome: Identification of novel lncRNAs associated with malignant progression and HPV infection. Oral Oncol. 2016; 59:58-66. doi: 10.1016/j.oraloncology.2016.05.014.

43. Wei G, Luo H, Sun Y, Li J, Tian L, Liu W, Liu L, Luo J, He J, Chen R. Transcriptome profiling of esophageal squamous cell carcinoma reveals a long noncoding RNA acting as a tumor suppressor. Oncotarget. 2015; 6:17065-80. doi: 10.18632/oncotarget.4185.

44. Takenobu M, Osaki M, Fujiwara K, Fukuhara T, Kitano H, Kugoh H, Okada F. PITX1 is a novel predictor of the 
response to chemotherapy in head and neck squamous cell carcinoma. Mol Clin Oncol. 2016; 5:89-94. doi: 10.3892/ mco.2016.880.

45. Nie FQ, Ma S, Xie M, Liu YW, De W, Liu XH. Decreased long noncoding RNA MIR31HG is correlated with poor prognosis and contributes to cell proliferation in gastric cancer. Tumour Biol. 2016; 37:7693-701. doi: 10.1007/ s13277-015-4644-z.

46. He A, Chen Z, Mei H, Liu Y. Decreased expression of LncRNA MIR31HG in human bladder cancer. Cancer Biomark. 2016; 17:231-6. doi: 10.3233/cbm-160635.

47. Shi Y, Lu J, Zhou J, Tan X, He Y, Ding J, Tian Y, Wang L, Wang K. Long non-coding RNA Loc554202 regulates proliferation and migration in breast cancer cells. Biochem Biophys Res Commun. 2014; 446:448-53. doi: 10.1016/j. bbrc.2014.02.144.

48. Montes M, Nielsen MM, Maglieri G, Jacobsen A, Hojfeldt J, Agrawal-Singh S, Hansen K, Helin K, van de Werken HJ, Pedersen JS, Lund AH. The lncRNA MIR31HG regulates p16(INK4A) expression to modulate senescence. Nat Commun. 2015; 6:6967. doi: 10.1038/ncomms 7967.

49. Qiu JJ, Yan JB. Long non-coding RNA LINC01296 is a potential prognostic biomarker in patients with colorectal cancer. Tumour Biol. 2015; 36:7175-83. doi: 10.1007/ s13277-015-3448-5.

50. Zou AE, Ku J, Honda TK, Yu V, Kuo SZ, Zheng H, Xuan Y, Saad MA, Hinton A, Brumund KT, Lin JH, WangRodriguez J, Ongkeko WM. Transcriptome sequencing uncovers novel long noncoding and small nucleolar RNAs dysregulated in head and neck squamous cell carcinoma. Rna. 2015; 21:1122-34. doi: 10.1261/rna.049262.114.

51. Zou AE, Zheng H, Saad MA, Rahimy M, Ku J, Kuo SZ, Honda TK, Wang-Rodriguez J, Xuan Y, Korrapati A, Yu V,
Singh P, Grandis JR, et al. The non-coding landscape of head and neck squamous cell carcinoma. Oncotarget. 2016; 7:51211-51222. doi: 10.18632/oncotarget.9979.

52. Gao W, Chan JY, Wong TS. Long non-coding RNA deregulation in tongue squamous cell carcinoma. Biomed Res Int. 2014; 2014: 405860. doi: 10.1155/2014/405860.

53. Zhang S, Tian L, Ma P, Sun Q, Zhang K, GuanchaoWang, Liu H, Xu B. Potential role of differentially expressed lncRNAs in the pathogenesis of oral squamous cell carcinoma. Arch Oral Biol. 2015; 60:1581-7. doi: 10.1016/j. archoralbio.2015.08.003.

54. Liu SJ, Horlbeck MA, Cho SW, Birk HS, Malatesta M, He D, Attenello FJ, Villalta JE, Cho MY, Chen Y, Mandegar MA, Olvera MP, Gilbert LA, et al. CRISPRi-based genomescale identification of functional long noncoding RNA loci in human cells. Science. 2017; 355. doi: 10.1126/science. aah7111.

55. Lohavanichbutr P, Houck J, Fan W, Yueh B, Mendez E, Futran N, Doody DR, Upton MP, Farwell DG, Schwartz SM, Zhao LP, Chen C. Genomewide gene expression profiles of HPV-positive and HPV-negative oropharyngeal cancer: potential implications for treatment choices. Arch Otolaryngol Head Neck Surg. 2009; 135:180-8. doi: 10.1001/archoto.2008.540.

56. Lohavanichbutr P, Houck J, Doody DR, Wang P, Mendez E, Futran N, Upton MP, Holsinger FC, Schwartz SM, Chen C. Gene expression in uninvolved oral mucosa of OSCC patients facilitates identification of markers predictive of OSCC outcomes. PLoS One. 2012; 7: e46575. doi: 10.1371/ journal.pone.0046575.

57. Gray KA, Yates B, Seal RL, Wright MW, Bruford EA. Genenames.org: the HGNC resources in 2015. Nucleic Acids Res. 2015; 43: D1079-85. doi: 10.1093/nar/gku1071. 